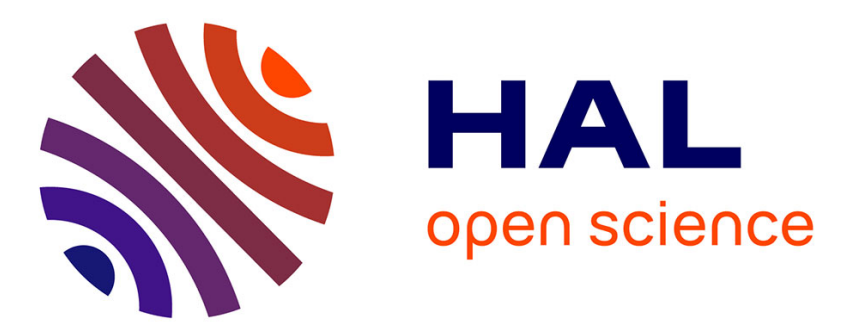

\title{
Hydrosoluble phosphonic acid functionalized poly(2-ethyl-2-oxazoline) chelating polymers for the sorption of metallic cations
}

Belkacem Tarek Benkhaled, Titouan Montheil, Vincent Lapinte, Sophie Monge

\section{To cite this version:}

Belkacem Tarek Benkhaled, Titouan Montheil, Vincent Lapinte, Sophie Monge. Hydrosoluble phosphonic acid functionalized poly(2-ethyl-2-oxazoline) chelating polymers for the sorption of metallic cations. Journal of Polymer Science, 2020, 58 (20), pp.2875-2886. 10.1002/pol.20200487 . hal03150406

\author{
HAL Id: hal-03150406 \\ https://hal.science/hal-03150406
}

Submitted on 23 Feb 2021

HAL is a multi-disciplinary open access archive for the deposit and dissemination of scientific research documents, whether they are published or not. The documents may come from teaching and research institutions in France or abroad, or from public or private research centers.
L'archive ouverte pluridisciplinaire $\mathbf{H A L}$, est destinée au dépôt et à la diffusion de documents scientifiques de niveau recherche, publiés ou non, émanant des établissements d'enseignement et de recherche français ou étrangers, des laboratoires publics ou privés. 


\title{
Hydrosoluble phosphonic acid functionalized poly(2-ethyl-2-oxazoline) chelating polymers for the sorption of metallic cations
}

\author{
Belkacem Tarek Benkhaled, Titouan Montheil, Vincent Lapinte, Sophie Monge \\ ICGM, Univ Montpellier, CNRS, ENSCM, Montpellier, France \\ Correspondence to: Vincent Lapinte (vincent.lapinte@umontpellier.fr) and Sophie Monge \\ (sophie.monge-darcos@umontpellier.fr)
}

Additional Supporting Information may be found in the online version of this article.

\begin{abstract}
In the present contribution, the synthesis of well-defined water-soluble phosphonic-acid based poly(2-ethyl-2-oxazoline) and the preliminary study of their sorption properties were reported. For such purpose, poly(2-ethyl-2-oxazoline) (POx) was first prepared. Then, controlled hydrolysis allowed the obtaining of statistical poly(2-ethyl-2-oxazoline)-stat-poly(ethyleneimine) (POx-st-PEI) with 20\% of ethyleneimine units, which allowed maintaining water solubility of the copolymers. The latter were successfully functionalized with either dimethyl(acryloyloxymethyl) phosphonate (APC1) or diethyl-2-(acrylamido)ethylphosphonate (DAAmEP) using Michael reaction. Phosphonated esters were hydrolyzed to produce phosphonic acid groups, thus leading to $h$ POx-st-PEI-APC1 and $h$ POx-stPEI-DAAmEP copolymers. Finally, functionalized statistical copolymers were successfully used for the sorption of divalent or trivalent metallic cations. The reported work aims at reporting the synthesis of original polyoxazoline materials functionalized with phosphonic acid groups that could be further employed for water treatment in polymer enhanced ultrafiltration processes.
\end{abstract}

KEYWORDS: polyoxazoline, phosphonic acid, sorption, metallic cations, water treatment

\section{INTRODUCTION}

Water pollution, which mainly results from domestic, industrial, commercial or agricultural activities, is a major concern in both developed and developing countries. As a result, it was essential to promote processes able to efficiently eliminate different kind of contaminants. ${ }^{1,2}$ Among the latter, removal of heavy metals was deeply considered, as they are often toxic, accumulate in living organisms, thus showing risks for human health. ${ }^{3,4}$ So, limits of release were defined for many countries for common heavy metals, 5,6 and many approaches were developed for the removal of metallic cations from wastewaters. ${ }^{7-}$

${ }^{9}$ Processes based on ions exchangers proved to be robust but led to limited selectivity. ${ }^{10-15}$ Chemical precipitation ${ }^{16,17}$ was also largely employed despite a limited recovery. Side to these processes, the use of membrane was a promising approach when coupled with hydrosoluble polymers bearing chelating agents. ${ }^{11,18,19}$ In this process called polymer enhanced ultrafiltration (PEUF), ${ }^{20-24}$ a watersoluble polymeric ligand showing high affinity for cations is added to the effluent to bind metallic cations via strong interactions. In a 
second step, water-soluble polymer/metallic cations complexes are filtered through an ultrafiltration (UF) membrane. Different functional polymers were already successfully employed in PEUF processes, ${ }^{25-28}$ achieving selective separation and recovery of heavy metals with low energy requirements. Chelating functional groups borne by the polymeric materials must be judiciously chosen to induce high sorption capacities and possibly selectivity. They often contained electron donor atoms such as oxygen, nitrogen, sulphur, or phosphorus. $^{28}$ Therefore polymers bearing alcohol or amine groups were deeply considered but special attention was paid to acid groups as they proved to be more interesting, notably due to their acidity constant, which led to either ion exchange or complexation depending on the chemical nature of the acidic functional group (carboxylic, sulfonic, or phosphonic acid moiety). In particular, phosphonic acid-based materials were widely studied for metal removal as they exhibited two dissociation constants $\left(\mathrm{pKa}_{1}=2-3\right.$ and $\left.\mathrm{pKa}_{2}=6-7\right){ }^{28-31}$ According to the pKa, sorption capacity of phosphonic acids at low $\mathrm{pH}$ proved to be interesting in comparison with other functional groups. When the $\mathrm{pH}$ was lower than 2, phosphonic acid groups were not dissociated thus forming coordination bonds with metallic cations. For a pH comprised between $\mathrm{pKa}_{1}$ and $\mathrm{pKa}_{2}$, only one hydroxyl was dissociated leading to the presence of two different mechanisms. Indeed, in this $\mathrm{pH}$ range, phosphonic acid behaved both as a polychelatogen with the complexation of metallic ions and as a polyelectrolyte with the electrostatic interactions with positively charged ions. Finally, at a pH higher than 7, sorption resulted from electrostatic forces as the two acid functions were dissociated. Additionally, it is also important to mention that sorption with phosphonic acid was not equivalent for all cations, notably with a higher sorption for trivalent cations in comparison with divalent ones. $^{31}$
In the present contribution, we report the accurate synthesis of new water-soluble phosphonic acid functionalized poly(2-ethyl-2oxazoline) for the removal of metallic cations. Whereas in the case of carboxylic acids, commercial polymers were available and could be directly used as chelating agents, phosphonic materials had to be synthesized. Several experimental methods were employed to obtain polymeric structures with cationremoval properties. Among the different strategies, the modification of commercial polymers by phosphorylation according to the Kabachnik-Fields reaction ${ }^{32}$ and the development of new functional monomers were prevalent. Nevertheless, examples dealing with hydrosoluble phosphonic acid based materials are still quite rare in the literature. For instance, phosphonic acid-based soluble polymers were considered for the selective sorption of $\mathrm{Gd}^{3+33}$, or $\mathrm{Ni}^{2+}$ and $\mathrm{Al}^{3+} \cdot{ }^{29,34-36}$ Watersoluble poly(ethylenimine) backbone bearing one phosphonic acid group at one chain end was used for the recovery of metals such as $\mathrm{Fe}^{3+}, \mathrm{U}^{6+},{ }^{37-39}$ and $\mathrm{Cu}^{2+}$. ${ }^{40}$ The introduction of phosphonic acid groups on biopolymers was also considered and proved to improve sorption capacity. Ramos et al. ${ }^{41}$ prepared and characterized chitosan modified with $\mathrm{N}$ methylene phosphonic groups. The resulting sorbents exhibited promising properties concerning the sorption of metallic ions such as $\mathrm{Cd}^{2+}, \mathrm{Cu}^{2+}, \mathrm{Fe}^{2+}$, and $\mathrm{Mg}^{2+}$. Phosphorylation reaction was carried out on different biosourced polymers such as cellulose, ${ }^{42}$ residue of starch extraction, ${ }^{43,44}$ cotton stalks, ${ }^{45}$ and sugarcane bagasse. ${ }^{46}$ Resulting phosphorylated biomaterials led to promising results for the sorption of different heavy metals.

Compared to phosphonated polymers already reported in the literature for metallic cation complexation, the phosphonic acid-based materials were developed from environmentally friendly polyoxazoline. Herein, the challenge was to combine poly(2-ethyl-2oxazoline) (POx) backbone with phosphonic acid moieties. Polyoxazoline was chosen for its 
biocompatibility, non-toxicity, its versatility, tunable properties, ${ }^{47-50}$ and to ensure hydrosolubility. It was first partially hydrolyzed to lead to poly(2-alkyl-2-oxazoline)-statpoly(ethylenimine) (POx-st-PEI), which allowed the introduction of phosphonated moieties. Indeed, the secondary amine groups of the PEI monomeric units acted as a nucleophile and allowed Michael addition reaction ${ }^{51}$ with phosphonated acrylate or acrylamide. After hydrolysis, water-soluble phosphonic acidbased polyoxazoline were evaluated for the sorption of two heavy metals of different valence, $\mathrm{Ni}^{2+}$ and $\mathrm{Al}^{3+}$. This contribution aims at reporting original synthetic procedures for the incorporation of chelating moieties onto nontoxic polyoxazoline.

\section{EXPERIMENTAL}

\subsection{Materials and methods}

Dichloromethane, methanol, ethanol, purchased from Sigma Aldrich, were organic synthesis grade, and used as received. Acetonitrile (Sigma Aldrich) was dried, distillated under vacuum from $\mathrm{CaH}_{2}$ (calcium hydride), and stored under a dry nitrogen atmosphere. Methyl p-toluenesulfonate (Sigma Aldrich, 98\%) was dried and distillated over $\mathrm{CaH}_{2}$. Poly(2-ethyl-2-oxazoline) $\left(\mathrm{M}_{\mathrm{n}}=20000\right.$ g. $\mathrm{mol}^{-1}, \oplus=3.07$ ) (Sigma Aldrich), 2-ethyl-2oxazoline (Sigma Aldrich, 99\%), dimethyl phosphite (Sigma Aldrich, 98\%), triethyl phosphite (Sigma Aldrich, 97.5\%), N-(2bromoethyl)phthalimide (Sigma Aldrich, 95\%), hydrazine monohydrate (Sigma Aldrich, 97.5\%), acryloyl chloride (Sigma Aldrich, 97\%), bromotrimethylsilane (Sigma Aldrich, 97\%), nickel(II) nitrate hexahydrate $\left(\mathrm{Ni}\left(\mathrm{NO}_{3}\right)_{2} \cdot 6 \mathrm{H}_{2} \mathrm{O}\right)$ (Sigma Aldrich, 98.5\%), aluminum nitrate nanohydrate $\left(\mathrm{Al}\left(\mathrm{NO}_{3}\right)_{3} .9 \mathrm{H}_{2} \mathrm{O}\right)$ (Sigma Aldrich, 98\%) were used without further purification.

\subsection{Analytical techniques}

${ }^{1} \mathrm{H} N M R,{ }^{13} \mathrm{C} N M R$, and ${ }^{31} \mathrm{P}$ NMR spectra were recorded using a Bruker Advance DRX 400 (400 $\mathrm{MHz}$ ) using $\mathrm{CDCl}_{3}, \mathrm{D}_{2} \mathrm{O}$ and methanol as deuterated solvent. For ${ }^{1} \mathrm{H} N M R$, chemical shifts were referenced to the peak of residual nondeuterated solvents at 7.26 and 4.79 ppm for $\mathrm{CDCl}_{3}$ and $\mathrm{D}_{2} \mathrm{O}$, respectively.

Molar mass distribution of polymers was determined by size exclusion chromatography (SEC) using a PL-GPC50 Plus (Agilent) equipped with a RI refractive index detector. Polar Gel M was used at $50{ }^{\circ} \mathrm{C}$ with a dimethylacetamide (DMAC) flow rate $(+0.1 \% \mathrm{LiCl}$ weight) equal to $0.8 \mathrm{~mL} \cdot \mathrm{min}^{-1}$, calibrated with PMMA standards. The concentration of $\mathrm{Ni}^{2+}$ ions in solution was determined with a Shimadzu High Performance Liquid Chromatography (HPLC) analyzer equipped with a Shim-Pack IC-C1 column and an IC-GC1 pre-column. The conductivity detector used was a CSS-6A operating at $40{ }^{\circ} \mathrm{C}$. The mobile phase was a mixture of tartric acid (4.0 mmol.L- $\left.{ }^{1}\right)$ and ethylenediamine $\left(1.4 \mathrm{mmol}^{-1}{ }^{-1}\right)$, with $1.5 \mathrm{~mL} \cdot \mathrm{min}^{-1}$ rate flow.

Atomic absorption spectroscopy (AAS) measurements were achieved using an AAS Thermo scientific ICE3000, and allowed the determination of the concentration of $\mathrm{Al}^{3+}$. The flame used in the analysis was a mix of nitrous oxide and acetylene. The wavelength of the detection was $310 \mathrm{~nm}$.

\subsection{Synthesis of phosphonated monomers}

\subsubsection{Synthesis of dimethyl(acryloyloxymethyl) phosphonate (APC1)}

In a first step, dimethylphosphite $(30 \mathrm{~g}, 273$ $\mathrm{mmol})$, paraformaldehyde $(9.02 \mathrm{~g}, 300 \mathrm{mmol})$ and potassium carbonate $\left(\mathrm{K}_{2} \mathrm{CO}_{3}\right)(1.87 \mathrm{~g}, 13.6$ mmol) were mixed in methanol $(150 \mathrm{~mL})$. The mixture was allowed to stir at room temperature for 2 hours. before filtration. Evaporation of methanol under reduced pressure led to the obtaining of the dimethyl(hydroxymethyl) phosphonate intermediate as an uncolored product $(37.5 \mathrm{~g}$, yield: $98 \%)$.

${ }^{1} \mathrm{H}$ NMR (400 MHz, $\left.\mathrm{CDCl}_{3}, \delta\right): 3.74(\mathrm{~d}, 2 \mathrm{H}$, $\left.\mathrm{C}_{2} \mathrm{OH}\right), 3.60\left(\mathrm{~d}, 6 \mathrm{H}, \mathrm{OCH}_{3}\right)$. 
In a second step, dimethyl(hydroxymethyl) phosphonate (30 g, $214 \mathrm{mmol})$, and triethylamine $\left(\mathrm{Et}_{3} \mathrm{~N}\right)(32.8 \mathrm{~mL}, 235 \mathrm{mmol})$ were dissolved in anhydrous dichloromethane (150 $\mathrm{mL})$. The reaction mixture was cooled at $0{ }^{\circ} \mathrm{C}$ and acryloyl chloride (19 mL, $235 \mathrm{mmol}$ ) was added dropwise. Mixture was allowed to stir at room temperature during 12 hours. After filtration to remove triethylammonium salt, dichloromethane $(50 \mathrm{~mL})$ was added and the organic phase was washed three times with a saturated solution of sodium bicarbonate in water $(3 \times 100 \mathrm{~mL})$. Organic phase was dried over anhydrous magnesium sulfate and evaporated under reduced pressure to lead to dimethyl(acryloyloxymethyl) phosphonate (APC1) (17.4 g, yield: 42\%).

${ }^{1} \mathrm{H}$ NMR $\left(400 \mathrm{MHz}, \mathrm{CDCl}_{3}\right), \delta: 6.31$ (dd, $1 \mathrm{H}$, $\left.\mathrm{CH}=\mathrm{C}_{2}{ }_{2}\right), 6.01\left(\mathrm{dd}, 1 \mathrm{H}, \underline{\mathrm{C}}=\mathrm{CH}_{2}\right), 5.76(\mathrm{dd}, 1 \mathrm{H}$, $\left.\mathrm{CH}=\mathrm{CH}_{2}\right), 4.33\left(\mathrm{~d}, 2 \mathrm{H}, \mathrm{OCH}_{2} \mathrm{P}\right), 3.65(\mathrm{~d}, 6 \mathrm{H}$, $\left.\mathrm{OCH}_{3}\right) ;{ }^{31} \mathrm{P}$ NMR $\left(\mathrm{CDCl}_{3}, 400 \mathrm{MHz}, \delta\right): 21.27$. Other characterization data: see Supporting Information, Figures S4 to S6.

\subsubsection{Synthesis of diethyl-2(acrylamido)ethyl phosphonate (DAAmEP)}

The synthesis of diethyl-2-(acrylamido)ethyl phosphonate (DAAmEP) was achieved following procedure reported in previous work. ${ }^{52}$

${ }^{1} \mathrm{H}$ NMR (400 MHz, $\left.\mathrm{D}_{2} \mathrm{O}, \delta\right): 6.15-6.35(\mathrm{~m}, 2 \mathrm{H}$, $\left.\mathrm{CH}_{2}=\right), 5.75-5.85(\mathrm{~m}, 1 \mathrm{H},=\mathrm{CH}), 4.10-4.25(\mathrm{~m}, 4 \mathrm{H}$, $\left.\mathrm{OCH}_{2}\right)$, 3.56-3.65 (m, $\left.2 \mathrm{H}, \mathrm{CH}_{2} \mathrm{~N}\right), 2.15-2.30(\mathrm{~m}$, $\left.2 \mathrm{H}, \mathrm{CH}_{2} \mathrm{P}\right), 1.30-1.40\left(\mathrm{t}, 6 \mathrm{H}, \mathrm{CH}_{3}\right) ;{ }^{31} \mathrm{P}$ NMR $\left(\mathrm{D}_{2} \mathrm{O}\right.$, $400 \mathrm{MHz}, \delta): 32.16$.

2.4 Cationic ring-opening polymerization (CROP) of 2-ethyl-2-oxazoline $\left(M_{n}\right.$ targeted $=$ 10000 g.mol ${ }^{-1}$ )

Cationic ring-opening polymerization was carried out under a dry nitrogen atmosphere. Methyl p-toluenesulfonate $(0.186 \mathrm{~g}, 1 \mathrm{mmol})$ and 2-ethyl-2-oxazoline (EtOx) (10 g, $100 \mathrm{mmol})$ were dissolved in dry acetonitrile $(30 \mathrm{~mL})$. The solution was vigorously stirred at $80{ }^{\circ} \mathrm{C}$ during 30 hours (monomer conversion, calculated from ${ }^{1} \mathrm{H}$ NMR comparing the signals at $4.5 \mathrm{ppm}$ and 2.31-2.46 ppm, attributed to the $\mathrm{OCH}_{2}$ in the monomer and the $\mathrm{CH}_{2}$ in $\alpha$ of the carbonyl in the polymer, respectively, was equal to $90 \%$ after 30 hours). Then, the polymerization was quenched at $40{ }^{\circ} \mathrm{C}$ by addition of an adequate amount of methanolic potassium hydroxide solution $\left(15 \mathrm{~mL}\right.$ at $\left.2 \mathrm{~mol}^{-1}\right)$. The flask was maintained at $40{ }^{\circ} \mathrm{C}$ overnight. After cooling, the reaction mixture was concentrated and then the poly(2-ethyl-2-oxazoline) (POx) was obtained after two successive precipitations in cold diethylether. Finally, polymer was dissolved in water $(10 \mathrm{~mL})$ and freeze-drying led to the obtaining of the POx as a fully dry white powder (8.4 g, yield: $84 \%$ )

${ }^{1} \mathrm{H}$ NMR $\left(400 \mathrm{MHz}, \mathrm{D}_{2} \mathrm{O}, \delta\right): 3.44-3.62(4 \mathrm{H}$, $\left.\mathrm{CH}_{2} \mathrm{CH}_{2} \mathrm{~N}\right), 2.31-2.46\left(2 \mathrm{H}, \mathrm{COCH}_{2} \mathrm{CH}_{3}\right), 1.05-1.09$ $\left(3 \mathrm{H}, \mathrm{COCH}_{2} \mathrm{CH}_{3}\right) ; \operatorname{SEC}(\mathrm{DMAC}): \mathrm{M}_{\mathrm{n}}=10400$ g. $\mathrm{mol}^{-1}, \oslash=1.31$.

\subsection{Typical procedure for the synthesis of poly(2-ethyl-2-oxazoline)-stat-poly(ethylene imine) (POx-st-PEI) by hydrolysis of the poly(2- ethyl-2-oxazoline) moiety}

It is important to mention that different hydrolysis degrees were obtained as a function of the reaction time.

Poly(2-ethyl-2-oxazoline) (15 g, $M_{n}=10400$ g. $\mathrm{mol}^{-1}, \emptyset=1.31$ ) was dissolved in distillated water $(100 \mathrm{~mL})$. Then, 37\% hydrochloric acid solution (150 $\mathrm{mL})$ was added dropwise, resulting in a $\mathrm{HCl}$ concentration equal to 6 mol. $L^{-1}$. The flask was placed in an oil bath during 75 minutes under reflux. Then, the mixture was cooled down to room temperature, and a $2.5 \mathrm{~mol}^{-\mathrm{L}^{-1}}$ sodium hydroxide solution was added until reaching a $\mathrm{pH}$ equal to 7 . Dialysis against water during 48 hours was carried out using $1 \mathrm{KDa}$ membrane. Finally, water was removed by freeze-drying and poly(2-ethyl-2oxazoline)-stat-poly(ethyl-eneimine) (POx-stPEI) was obtained as a white powder (12 g, yield: $85 \%$, hydrolysis degree $=20 \%$ ) .

${ }^{1} \mathrm{H} \quad \mathrm{NMR} \quad\left(400 \quad \mathrm{MHz}, \quad \mathrm{D}_{2} \mathrm{O}, \quad \delta\right): \quad 3.15-3.62$ $\left(\mathrm{CH}_{2} \mathrm{CH}_{2} \mathrm{~N}(\mathrm{COEt})\right), 2.70-2.90\left(\mathrm{CH}_{2} \mathrm{C}_{2} \mathrm{NH}\right), 2.31-$ $2.46\left(\mathrm{COC}_{2} \mathrm{CH}_{3}\right)$, 1.05-1.09 $\left(\mathrm{COCH}_{2} \underline{\mathrm{CH}}_{3}\right)$. 
2.6 Functionalization of poly(2-ethyl-2oxazoline)-stat-poly(ethyleneimine) (POx-stPEI) by Michael addition

The functionalization of POx-st-PEI was achieved using the same procedure either with dimethyl(acryloyloxymethyl) phosphonate (APC1) or diethyl-2-(acrylamido)ethyl phosphonate (DAAmEP).

In a typical experiment, POx-st-PEI statistic copolymer $(2 \mathrm{~g})$ was dissolved in methanol (60mL). Dimethyl(acryloyloxymethyl) phosphonate (APC1) or diethyl-2(acrylamido)ethyl phosphonate (DAAmEP) (2 molar equivalents with respect to $\mathrm{PEI}$ monomeric unit) was added dropwise. Resulting reaction mixture was heated at $60{ }^{\circ} \mathrm{C}$ during 24 hours. Then, the solvent was evaporated under reduced pressure. The crude material was dialyzed against water during 48 hours. POx-stPEI functionalized with either APC1 (POx-st-PEIAPC1) or DAAmEP (POx-st-PEI-DAAmEP) was obtained as a yellow powder (1.4 g, yield: $75 \%$ ) after freeze-drying.

POx-st-PEI-APC1: ${ }^{1} \mathrm{H}$ NMR (400 MHz, $\left.\mathrm{D}_{2} \mathrm{O}, \delta\right)$ : $4.20\left(\mathrm{OCH}_{2} \mathrm{P}\right), 3.41-3.75\left(\mathrm{CH}_{2} \mathrm{~N}(\mathrm{COEt}), \mathrm{OCH}_{3}\right)$, 2.53-3.10 ( $\left.\mathrm{NC}_{2}\right), 2.29-2.53\left(\mathrm{COC}_{2} \mathrm{CH}_{3}\right), 1.25-$ $1.35\left(\mathrm{CH}_{2} \mathrm{CH}_{2} \mathrm{C}(\mathrm{O}) \mathrm{O}\right), 1.01-1.15\left(\mathrm{COCH}_{2} \mathrm{CH}_{3}\right) ;{ }^{31} \mathrm{P}$ NMR (400 MHz, $\left.\mathrm{D}_{2} \mathrm{O}, \delta\right): 28.8 \mathrm{ppm}$.

POx-st-PEI-DAAmEP: ${ }^{1} \mathrm{H}$ NMR $\left(400 \mathrm{MHz}, \mathrm{D}_{2} \mathrm{O}, \delta\right)$ : 4.13-4.20 (OCH $\left.{ }_{2}\right), \quad 3.41-3.70 \quad\left(\mathrm{CH}_{2} \mathrm{~N}(\mathrm{COEt})\right.$, $\left.\mathrm{NHCH}_{2} \mathrm{CH}_{2} \mathrm{P}\right), \quad 2.58-2.90 \quad\left(\mathrm{NC}_{2}\right), \quad 2.29-2.51$ $\left(\mathrm{COCH}_{2} \mathrm{CH}_{2}, \mathrm{COC}_{2} \mathrm{CH}_{3}\right), 2.13-2.24\left(\mathrm{CH}_{2} \mathrm{P}\right), 1.32$ $1.38\left(\mathrm{P}(\mathrm{O}) \mathrm{CH}_{2} \mathrm{C}_{3}\right), 1.02-1.15\left(\mathrm{COCH}_{2} \underline{\mathrm{CH}}_{3}\right) ;{ }^{31} \mathrm{P}$ NMR (400 MHz, $\left.\mathrm{D}_{2} \mathrm{O}, \delta\right): 32 \mathrm{ppm}$.

\subsection{General procedure for the hydrolysis of the phosphonated ester into phosphonic acid groups}

Trimethylsilyl bromide (5 molar equivalents with respect to phosphonated group) was added to a solution of polymer $(1 \mathrm{~g})$ in anhydrous dichloromethane $(100 \mathrm{~mL})$ under nitrogen atmosphere. After stirring for 12 hours at room temperature, the mixture was concentrated under reduced pressure. Methanol $(80 \mathrm{~mL})$ was added and the mixture was stirred for 2 hours at room temperature. A dialysis against $1 \%$ wt. of potassium hydroxide water solution of the mixture was carried out during 6 hours and hydrolyzed polymer was obtained by freeze-drying ( $0.95 \mathrm{~g}$, yield: $95 \%)$. hPOx-st-PEI-APC1: ${ }^{1} \mathrm{H}$ NMR (400 MHz, $\mathrm{D}_{2} \mathrm{O}, \delta$ ): $4.20\left(\mathrm{OCH}_{2} \mathrm{P}\right), 3.41-3.74\left(\mathrm{C}_{2} \mathrm{~N}(\mathrm{COEt})\right), 2.53-3.10$ $\left(\mathrm{NC}_{2}\right), \quad 2.29-2.53 \quad\left(\mathrm{COC}_{2}{ }_{2} \mathrm{CH}_{3}\right), \quad 1.01-1.15$ $\left(\mathrm{COCH}_{2} \mathrm{CH}_{3}\right) ;{ }^{31} \mathrm{P}$ NMR $\left(400 \mathrm{MHz}, \mathrm{D}_{2} \mathrm{O}, \delta\right): 28.8$ ppm.

hPOx-st-PEI-DAAmEP: ${ }^{1} \mathrm{H}$ NMR $\left(400 \mathrm{MHz}, \mathrm{D}_{2} \mathrm{O}\right.$, ठ): 3.41-3.70 ( $\left.\underline{\mathrm{C}}_{2} \mathrm{~N}(\mathrm{COEt}), \mathrm{NHC}_{2} \mathrm{CH}_{2} \mathrm{P}\right), 2.58-$ 2.90 ( $\mathrm{NC}_{2}$ ), 2.29-2.51 ( $\mathrm{COCH}_{2} \mathrm{CH}_{2}, \mathrm{COCH}_{2} \mathrm{CH}_{3}$, $\left.\mathrm{CH}_{2} \mathrm{P}\right), 1.02-1.13\left(\mathrm{COCH}_{2} \mathrm{C}_{3}\right) ;{ }^{31} \mathrm{P}$ NMR $(400$ $\left.\mathrm{MHz}, \mathrm{D}_{2} \mathrm{O}, \delta\right): 34 \mathrm{ppm}$.

\subsection{Sorption experiments}

Sorption experiments were carried out using dialysis: $10 \mathrm{~mL}$ of copolymer aqueous solution with a concentration equal to $5 \mathrm{~g} . \mathrm{L}^{-1}$ were introduced in a tubular ester cellulose dialysis membrane (molecular weight cut-off of 2000 g. $\left.\mathrm{mol}^{-1}\right)$. The latter was then immersed in a 100 $\mathrm{mL}$ bulk solution containing $5 \mathrm{~g} \cdot \mathrm{L}^{-1}$ of $\mathrm{Ni}^{2+}$ or $\mathrm{Al}^{3+}$ ions (see Supporting Information). The temperature was fixed at $25^{\circ} \mathrm{C}$ by a water bath equipped with a setback thermostat. The copolymer in the inner solution could not migrate in the bulk solution because the molecular weight of copolymer chains was higher than the molecular weight cut-off of the dialysis membrane. The amount of ions trapped by the copolymer was determined by measuring the concentration of the $\mathrm{Ni}^{2+}$ or $\mathrm{Al}^{3+}$ cations studied in the bulk solution before and after sorption experiments.

When thermodynamic equilibrium was reached, the concentrations of free ions in dialysis and in bulk were considered as equal $\left(C_{\text {bulk }}=C_{\text {dial }}\right)$. The initial concentration of cation $\left(C_{0}\right)$ was considered in the total volume of the system and was calculated from Equation (1):

$$
\mathrm{C}_{0}=\frac{\mathrm{C}_{\text {bulk }} \times \mathrm{V}_{\text {bulk }}}{\mathrm{V}_{\mathrm{bulk}}+\mathrm{V}_{\text {dial }}}
$$

where $C_{\text {bulk }}$ and $V_{\text {bulk }}$ are the concentration and volume of the bulk solution (out of dialysis), 
respectively, $V_{\text {dial }}$ is the volume of the dialysis membrane containing the polymer solution.

Ionic chromatography and atomic absorption spectroscopy were used for the analysis of nickel and aluminum cations, respectively. Before analysis, the bulky solution was diluted to the appropriate concentration for HPLC and AAS experiments. Experimental details concerning the calculation of the metallic cations concentration are given in the supporting information. After dilution of the bulky solution, the initial concentration of nickel and aluminum were measured to be equal to $\mathrm{C}_{\mathrm{Ni}^{2+}}=1.562$, and $\mathrm{C}_{\mathrm{Al}^{3+}}=1.208 \mathrm{mmol} \cdot \mathrm{L}^{-1}$, by HPLC and AAS, respectively. These concentrations were in all cases in large excess in comparison with concentration of phosphonic acid groups borne by the copolymers. The $\mathrm{pH}$ of the final solution was adjusted to 7 by adding a small amount of sodium hydroxide solution $(\mathrm{NaOH} 5$ $\%$ wt.).

\section{RESULTS AND DISCUSSION}

\subsection{Synthesis of phosphonic acid-based poly(2- ethyl-2-oxazoline)}

The synthesis of original water-soluble polyoxazolines functionalized with phosphonic acid groups was achieved according to original reactional pathway (Scheme 1) allowing a perfect control of the chemical composition of the overall copolymers. Poly(2-ethyl-2oxazoline) and phosphonic acid groups were notably chosen due to its excellent water solubility, and their capacity to efficiently sorb metallic cations, respectively. First step dealt with the synthesis of poly(2-ethyl-2-oxazoline) (prepared POx) with controlled molecular weight and low dispersity $(\Theta)$. Then, partial hydrolysis was carried out to produce secondary amine functions while keeping hydrosolubility of the material (POx-st-PEI). Functionalization reaction via the amine groups was performed to introduce phosphonated ester moieties using Michael reaction, in the presence of either dimethyl(acryloyloxymethyl) phosphonate (APC1) (POx-st-PEI-APC1) or diethyl-2-(acrylamido)ethyl phosphonate
(DAAmEP) (POx-st-PEI-DAAmEP). Finally, hydrolysis of the phosphonated ester functions was performed and hydrosoluble phosphonic acid-based materials ( $h$ POx-st-PEI-APC1 and $h$ POx-st-PEI-DAAmEP), able to complex metallic cations, were obtained.

Two different poly(2-ethyl-2-oxazoline)s were used. The first one was a commercial product, with a molecular weight and a dispersity (measured by size exclusion chromatography) equal to $M_{n}=20000 \mathrm{~g} \cdot \mathrm{mol}^{-1}$, and $\theta=3.07$, respectively. The second one was synthesized by cationic ring-opening polymerization. In the latter case, the targeted molecular weight was equal to 10000 g.mol ${ }^{-1}$. Cationic ring-opening polymerization of 2-ethyl-2-oxazoline (EtOx) was carried out in dry acetonitrile at $80^{\circ} \mathrm{C}$ using methyl p-toluenesulfonate as initiator during 30 hours. Monomer conversion was determined by comparing the signals at $4.5 \mathrm{ppm}$ and 2.31-2.46 ppm, attributed to the $\mathrm{OCH}_{2}$ in the monomer and the $\mathrm{CH}_{2}$ in $\alpha$ of the carbonyl in the polymer, respectively. The polymerization was quenched at $40{ }^{\circ} \mathrm{C}$ by adding methanolic potassium hydroxide solution. Poly(2-ethyl-2-oxazoline) (POx) was obtained in good yield (84\%) after two successive precipitations in cold diethylether, and a freeze-drying of polymer in water. ${ }^{1} \mathrm{H}$ NMR spectrum in deuterated water (Figure S1, Supporting Information) allowed characterizing the POx with signals at 3.44-3.62 $\mathrm{ppm}$ attributed to methylene groups of the main chain, and at 2.31-2.46 and 1.05-1.09 ppm, for the methylene and the methyl group of the lateral chain, respectively. Size exclusion chromatography (Figure S2, Supporting Information) in dimethylacetamide (DMAC) using poly(methyl methacrylate) (PMMA) standards showed a molecular weight, and a dispersity equal to $M_{n}=10400$ g.mol ${ }^{-1}$, and $\emptyset=$ 1.31, respectively. To conclude, two poly(2ethyl-2-oxazoline) with two different molecular weights and dispersities were then employed for further experiments to study the influence of these parameters on sorption properties: a synthesized one (prepared POx) and a 


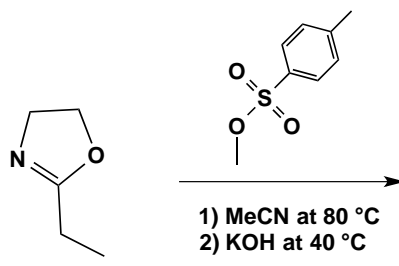

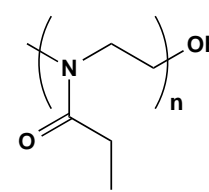

POx

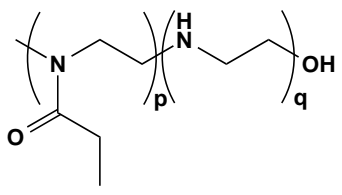

POx-st-PEI

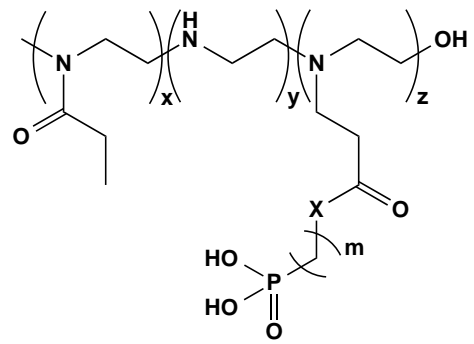

hPOX-st-PEI-APC1: $\mathrm{X}=0, \mathrm{~m}=1$ hPOX-st-PEI-DAAmEP: $\mathrm{X}=\mathrm{NH}, \mathrm{m}=2$
1) $\mathrm{Me}_{3} \mathrm{SiBr}, \mathrm{DCM}$ 2) $\mathrm{MeOH}$
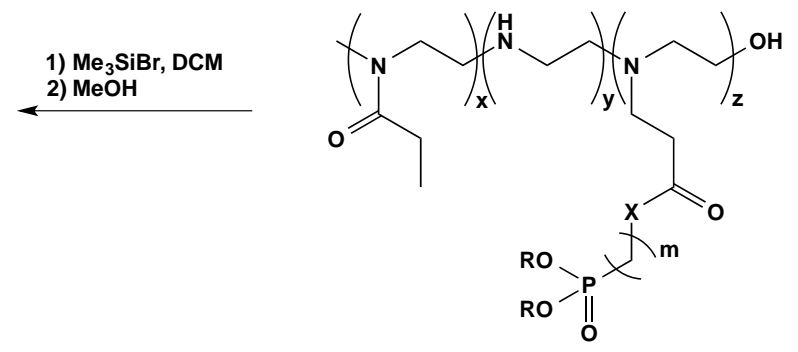

POX-st-PEI-APC1: $X=0, m=1, R=M e$ POX-st-PEI-DAAmEP: $X=\mathrm{NH}, \mathrm{m}=2, \mathrm{R}=\mathrm{Et}$

SCHEME 1 Reactional pathway for the synthesis of functionalized polyoxazoline-based copolymers ( $h$ POx-st-PEI-APC1 and $h$ POx-st-PEI-DAAmEP).

TABLE 1 Main characteristics of poly(2-ethyl-2-oxazoline) used for functionalization reactions

\begin{tabular}{llcc}
\hline Polymer name & Source & $\mathbf{M}_{\mathbf{n}}{ }^{{ }^{a}}$ & $\boldsymbol{\Phi}^{a}$ \\
\hline prepared POx & synthesized & 10400 & 1.31 \\
POx & commercial & 20000 & 3.07 \\
\hline
\end{tabular}

${ }^{\text {a }}$ determined by size exclusion chromatography using dimethylacetamide (DMAc) as solvent and poly(methyl methacrylate) (PMMA) standards.

commercial one (POx). Accurate characteristics of both poly(2-ethyl-2-oxazoline) are gathered in Table 1. It is important to notice that all results shown in the main manuscript dealt with commercial poly(2-ethyl-2-oxazoline) as starting material whereas all characterizations obtained from synthesized poly(2-ethyl-2- oxazoline) are reported in the Supporting Information, as mentioned throughout the manuscript.

Second step of the synthesis dealt with the introduction, in the polymeric structure, of groups that could be used for the functionalization with phosphonated moieties. So, it was decided to achieve a partial hydrolysis of the POx to get reactive secondary amine functions, obtaining poly(2-ethyl-2-oxazoline)stat-poly(ethyleneimine) (POx-st-PEI) statistical copolymers (Scheme 1). Reaction was performed under reflux in distillated water in the presence of hydrochloric acid $6 \mathrm{M}$ solution. ${ }^{53,54}$ Kinetics of the hydrolysis were measured (Figure 1 and Figure S3, Supporting information), as it was important to introduce secondary amine along the macromolecular chain while keeping solubility of the copolymer 
in water. ${ }^{1} \mathrm{H}$ NMR analysis was achieved every 10 minutes to determine both conversion and hydrolysis degree. The latter was calculated by comparing the integration of the methylene groups in the main chain of the oxazoline unit at 3.15-3.62 ppm with the methylene in $\alpha$ of the nitrogen atom in the ethyleneimine unit at 2.70-2.90 ppm (Figure 2 and Figure S3, Supporting Information). After appropriate reaction time, poly(2-ethyl-2-oxazoline)-statpoly(ethyleneimine) (POx-st-PEI) copolymers were recovered by dialysis against water followed by freeze-drying with good yields (in the order of $85 \%)$. Water solubility was studied at room temperature $\left(25^{\circ} \mathrm{C}\right)$, in milli-Q water at neutral $\mathrm{pH}(\mathrm{pH}=7)$.

As expected, the hydrolysis degree increased with time and the solubility of the copolymers decreased with hydrolysis degree. Indeed, POx$s t$-PEl copolymers became insoluble in water for a hydrolysis degree above $25 \%$ at a fixed copolymer concentration equal to $5 \mathrm{~g} \cdot \mathrm{L}^{-1}$ in milli-Q water at $25{ }^{\circ} \mathrm{C}$. As a result, it was decided to work with copolymers showing hydrolysis degree around $20 \%$, thus allowing relatively high content in ethylenimine unit, further used for appropriate functionalization, while keeping solubility in water. It was noticed that the hydrolysis of poly(2-ethyl-2-oxazoline) was similar whatever was the molecular weight or dispersity of the polymer, as already reported in the literature, ${ }^{53}$ as reaction on prepared and commercial poly(2-ethyl-2oxazoline) led to similar results. Finally, it is important to mention that partial hydrolysis of polyoxazoline proved to depend on the $\mathrm{HCl}$ concentration and on the temperature, thus explaining differences observed in comparison with the literature. ${ }^{53}$ In our particular case, same experimental conditions led to identical hydrolysis degree, notably with $20 \%$ hydrolysis, proving the reproducibility of the reaction.

Next step of the synthesis dealt with the functionalization of the secondary amine functions of the POx-st-PEI copolymers to introduce phosphonated ester groups able, after hydrolysis into phosphonic acid moieties, to complex with metallic cations. Functionalization reaction was achieved using Michael addition reaction as it appeared as a prized tool in materials science due to its click nature. Indeed, such reaction proved to be quick, highly efficient and do not produce side products. In the present case, Michael addition

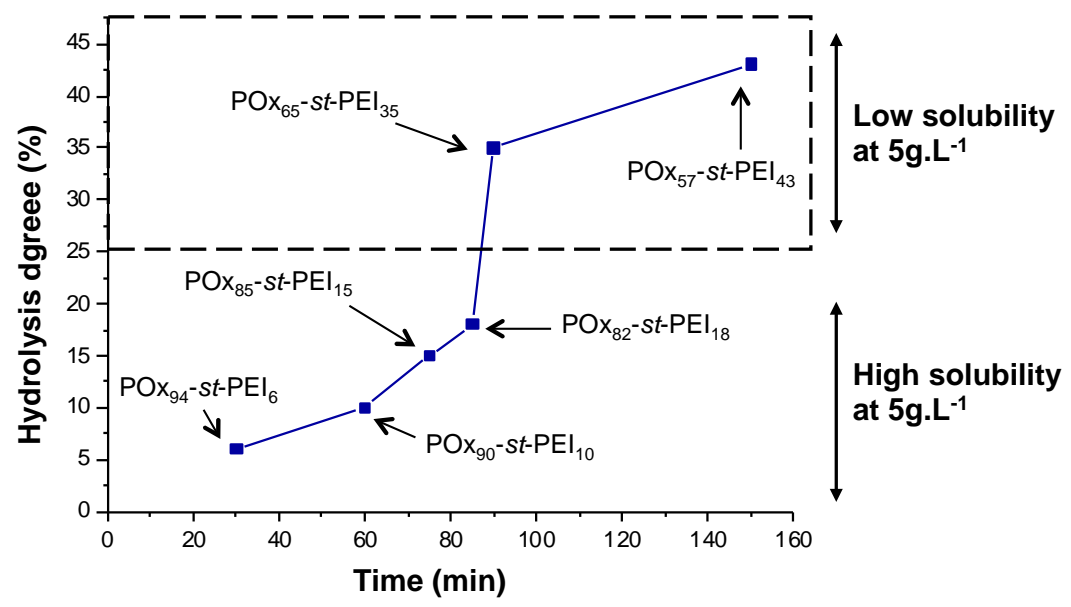

FIGURE 1 Determination of the hydrolysis degree as a function of time for the hydrolysis of the commercial poly(2-ethyl-2-oxazoline) (POx). In the general formula $\mathrm{POx}_{\mathrm{p}}-s t-\mathrm{PEI}_{\mathrm{q}}, \mathrm{p}$ and $\mathrm{q}$ are the percentage of 2-ethyl-2-oxazoline and ethyleneimine units, respectively. Reaction conditions: $37 \%$ 
hydrochloric acid solution concentration: 6 mol. $\mathrm{L}^{-1}$ under reflux. Solubility conditions: copolymer concentration: 5 g. $\mathrm{L}^{-1}$, in milli-Q water at $25^{\circ} \mathrm{C}$.

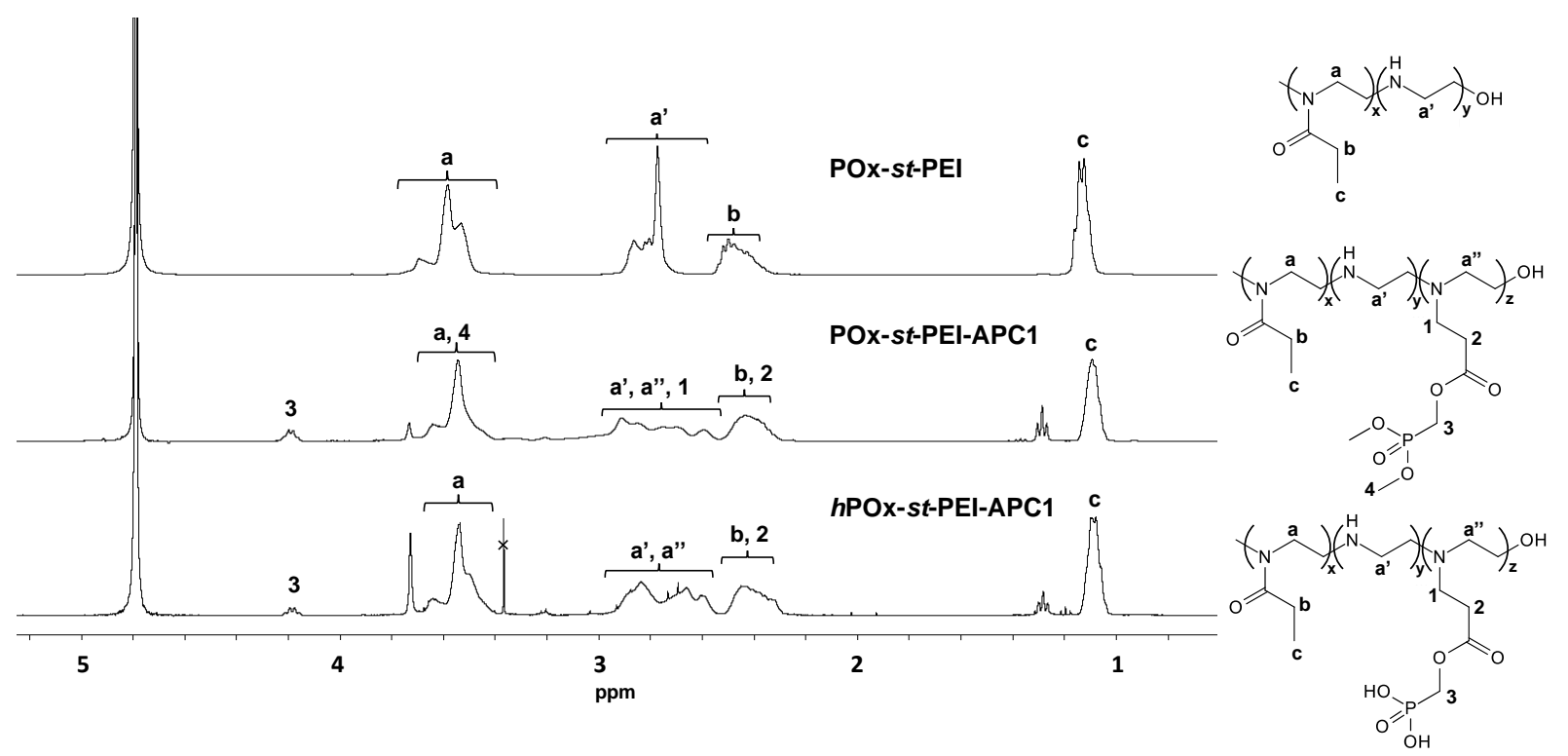

FIGURE 2. ${ }^{1} \mathrm{H}$ NMR spectra in deuterated water for POx-st-PEI (top), POx-st-PEI-APC1 (middle) and $h$ POxst-PEI-APC1 (bottom). POx used is the commercial one.

TABLE 2 Characteristics of POx-st-PEI copolymers before and after functionalization with dimethyl(acryloyloxymethyl) phosphonate (APC1) or diethyl-2-(acrylamido)ethylphosphonate) (DAAmEP)

\begin{tabular}{|c|c|c|c|c|c|c|c|c|}
\hline \multirow{2}{*}{ Polymer name } & \multicolumn{4}{|c|}{ Molar percentage (\%) } & \multicolumn{4}{|c|}{ Number of units } \\
\hline & $\mathrm{EtOx}^{\mathrm{c}}$ & $E I^{d}$ & APC1 & DAAmEP & $\mathrm{EtOx}^{\mathrm{C}}$ & $\mathrm{El}^{\mathrm{d}}$ & APC1 & DAAmEF \\
\hline POx-st-PEI-APC1 ${ }^{\text {a }}$ & 80 & 12 & 8 & - & 81 & 12 & 8 & - \\
\hline POx-st-PEI-DAAmEP ${ }^{a}$ & 80 & 6.5 & - & 13.5 & 81 & 7 & - & 13 \\
\hline POx-st-PEI-APC1 ${ }^{\mathrm{b}}$ & 80 & 8 & 12 & - & 161 & 16 & 25 & - \\
\hline POx-st-PEI-DAAmEP ${ }^{b}$ & 80 & 11 & - & 9 & 161 & 23 & - & 18 \\
\hline
\end{tabular}

${ }^{a}$ copolymer prepared from synthesized poly(2-ethyl-2-oxazoline); ${ }^{b}$ copolymer prepared from commercial poly(2-ethyl-2oxazoline); ${ }^{c}$ EtOx: 2-ethyl-2-oxazoline; ${ }^{d}$ El: ethyleneimine

took place between a nucleophile (secondary amine as Michael donor) on an activated electrophile ( $\alpha, \beta$-unsaturated carbonylic compound such as acrylate or acrylamide as Michael acceptor). ${ }^{55,56}$ Functionalization was carried out with a phosphonated acrylate or acrylamide, namely the dimethyl(acryloyloxymethyl) phosphonate (APC1) or the diethyl-2-(acrylamido)ethyl phosphonate) (DAAmEP), respectively (Scheme 1). APC1 and DAAmEP were first prepared.Synthesis of APC1 was carried out using experimental procedure developed for the synthesis of dimethyl(methacryloyloxy)methyl phosphonate (MAPC1). ${ }^{57}$ In the first step, dimethylphosphite reacted with paraformaldehyde in methanol at room temperature to lead to dimethyl hydroxymethylphosphonate in quantitative yield. Then, the second step corresponded to the acryloylation of the hydroxyl group with acryloyl chloride in dichloromethane in the presence of triethylamine. APC1 was obtained in satisfactory yield (around 40\%). Synthesis of DAAmEP was performed using experimental procedure already described in the literature. ${ }^{52}$ 
Both APC1 and DAAmEP were characterized by ${ }^{1} \mathrm{H}$ and ${ }^{31} \mathrm{P}$ NMR (Figures S4-S8, Supporting
Information). Functionalization of POx-st-PEI was achieved on copolymers with hydrolysis
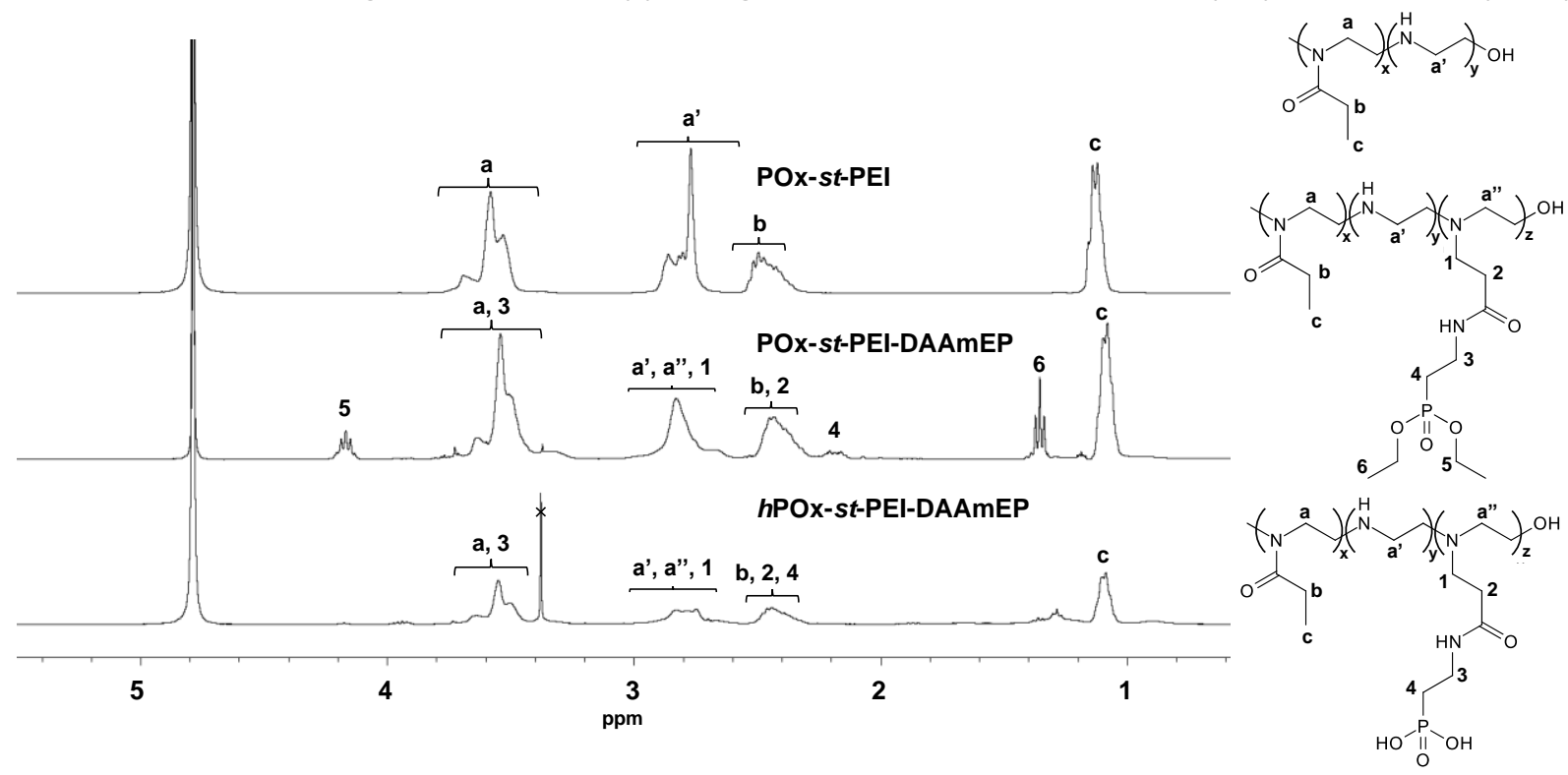

FIGURE 3. ${ }^{1} \mathrm{H}$ NMR spectra in deuterated water for POx-st-PEI (top), POx-st-PEI-DAAmEP (middle) and $h P O x$-st-PEI-DAAmEP (bottom). POx used is the commercial one.

degree equal to $20 \%$ (Table 2) by Michael addition reaction using secondary amine functional groups of the main polymeric chain, which reacted with either APC1 or DAAmEP (Scheme 1). Reaction was carried out in methanol at $60{ }^{\circ} \mathrm{C}$ during 24 hours. Maximum conversion was determined to be equal to 70 and $80 \%$, for functionalization with acrylate and acrylamide derivatives, respectively. Modified copolymers were recovered by dialysis against water during 48 hours. POx-st-PEI functionalized with either APC1 acrylate (POxst-PEI-APC1) or DAAmEP acrylamide (POx-stPEI-DAAmEP) was obtained as yellow powders after freeze-drying. Functionalization rates were determined by ${ }^{1} \mathrm{H}$ NMR (Figures 2 and 3), comparing the integration of the signals corresponding to the methylene in $\alpha$ position of the amide function, in the $\mathrm{N}$-acyl ethyleneimine unit (2.29-2.51 ppm, protons a), with the one attributed to the methylene between the oxygen and the phosphorus atoms at $4.20 \mathrm{ppm}$ (protons 3 in POx-st-PEI-APC1, Figure 2) or to the methylene of the ethylphosphonate group at 4.13-4.20 ppm (protons 5 in POx-st-PEI-
DAAmEP, Figure 3) for functionalization reaction with APC1 or DAAmEP, respectively. Functionalization rates were slightly higher with DAAmEP acrylamide derivative $(12 \%$ on average) in comparison with APC1 acrylate one ( $10 \%$ on average). Additionally, it was also interesting to mention that, in all cases, once copolymers purified, 40 to $65 \%$ of the ethyleneimine units were functionalized. Finally, polymer molecular weight did not have an influence on the rates, which were close whatever the polyoxazoline employed. ${ }^{1} \mathrm{H}$ NMR spectra analysis allowed proving the obtaining of the targeted functionalized copolymers. For instance, in the case of POx-st-PEI-APC1, signal at $4.20 \mathrm{ppm}$ was characteristic of the APC1 moiety as it was attributed to the methylene in $\alpha$ of the phosphorus atom whereas other protons coming from APC1 overlapped with signals of the POx-st-PEI segments $\left({ }^{1} \mathrm{H}\right.$ NMR spectrum for copolymer prepared from synthesized POx, Figure S9, Supporting Information). Concerning POx-st-PEI-DAAmEP copolymers, signals at 4.13-4.20, 2.13-2.24, and 1.32-1.38 ppm were attributed to DAAmEP 
moiety, corresponding to the methylene of the phosphonated group, the methylene in $\alpha$ of the phosphorus atom, and the methyl of the phosphonated group, respectively $\left({ }^{1} \mathrm{H}\right.$ NMR

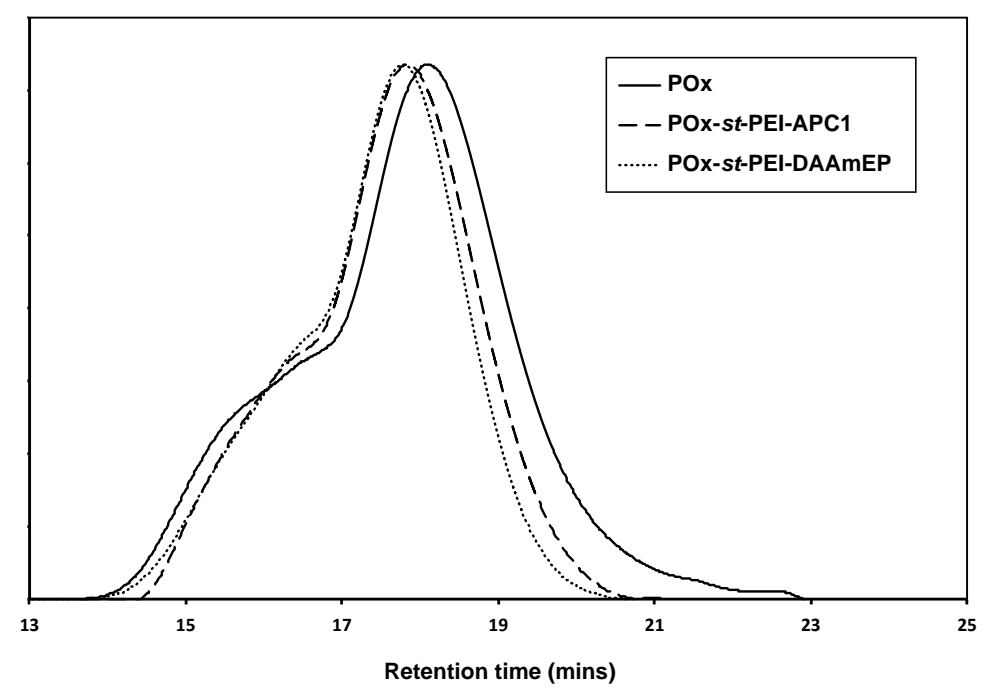

FIGURE 4. Size exclusion chromatograms in dimethylacetamide (DMAc) of commercial poly(2-ethyl-2oxazoline) (POx) and copolymers obtained after partial hydrolysis and functionalization with dimethyl(acryloyloxymethyl) phosphonate (APC1) or diethyl-2-(acrylamido)ethyl phosphonate (DAAmEP), leading to POx-st-PEI-APC1 or POx-st-PEI-DAAmEP copolymers, respectively.

spectrum for copolymer prepared from synthesized POx, Figure S10, Supporting Information). ${ }^{31} \mathrm{P} \quad \mathrm{NMR}$ also allowed characterizing synthesized POx-st-PEI-APC1 and POx-st-PEI-DAAmEP with the presence of a signal at 28.8 and $32 \mathrm{ppm}$, respectively, attributed to the phosphonated groups (Figures S11 and S12, Supporting Information). Characterization of the copolymers by size exclusion chromatography showed the increase of the retention time after partial hydrolysis and functionalization with APC1 acrylate or DAAmEP acrylamide, thus demonstrating an increase in the molecular weight without any side-reaction (Figure 4). All experimental results confirmed that the functionalization reaction was successful, which led to the introduction of phosphonated ester functions onto watersoluble poly(2-ethyl-2-oxazoline)-statpoly(ethylenimine) copolymers. In order to improve sorption of metallic cations, last chemical reaction was the hydrolysis of the phosphonated ester into phosphonic acid groups. Reaction was carried out at room temperature with trimethylsilyl bromide in anhydrous dichloromethane (DCM) under nitrogen (Scheme 1). After concentration of the reaction mixture, methanol was added. Hydrolyzed polymers ( $h P O x-s t-P E I-A P C 1$ and $h \mathrm{POx}$-st-PEI-DAAmEP) were obtained in very good yields. As hydrochloric acid was released during the hydrolysis, ethyleneimine units got protonated to ammonium. So, dialysis was achieved against $1 \%$ wt. of potassium hydroxide solution to neutralize the copolymer followed by freeze-drying. Characterization by ${ }^{1} \mathrm{H}$ NMR spectroscopy (Figures 2 and 3, and Figures S13 and S14, Supporting Information) proved that the hydrolysis was successful, in particular for hPOx-st-PEI-DAAmEP copolymer with the disappearance of the signals at 4.13-4.20 and 1.32-1.38 ppm (attributed to the ethoxy group borne by the phosphonated ester group) after hydrolysis. Additionally, a slight chemical shift was observed for the methylene in $\alpha$ of the phosphorus atom (from 2.13-2.24 to 2.29-2.51 ppm). For POx-st-PEI-APC1, ${ }^{1} \mathrm{H}$ NMR spectrum did not allow confirming hydrolysis as the methyl group associated to the phosphonated group overlapped with the methylene of the 
main chain in the oxazoline unit. Instead, ${ }^{31} \mathrm{P}$ NMR proved the obtaining of phosphonic acid groups as the signal shifted from 28.8 to 22.3 ppm for hPOx-st-PEI-APC1 (Figure S11, Supporting Information). Same trend was found in the case of $h$ POx-st-PEI-DAAmEP with a shift from 32 to $34 \mathrm{ppm}$ (Figure S12, Supporting Information).

To conclude, the synthesis of well-defined phosphonic acid based-poly(2-ethyl-2oxazoline)s was successfully achieved, notably achieving a partial hydrolysis of $\mathrm{N}$-acylethyleneimine into ethyleneimine units in order to maintain water solubility. Secondary amines were then used for the introduction of phosphonated groups via Michael reaction by appropriate reaction with phosphorus based acrylate or acrylamide. Finally, hydrolysis of phosphonated ester led to phosphonic acid groups, which are known in the literature to efficiently sorb metallic cations. So, the last part of this contribution deals with preliminary study for the sorption of nickel and aluminium cations.

\subsection{Preliminary study of the sorption of $\mathrm{Ni}^{2+}$} and $\mathrm{Al}^{3+}$ metallic cations

Last part of the reported work deals with preliminary study of sorption properties of the well-defined water-soluble phosphonic acidbased poly(2-ethyl-2-oxazoline). hPOx-st-PEIAPC1 and $h$ POx-st-PEI-DAAmEP copolymers prepared from commercial or synthesized poly(2-ethyl-2-oxazoline) were used for the sorption of either nickel divalent or aluminum trivalent cations. For such purpose, concentration of $\mathrm{Ni}^{2+}$ and $\mathrm{Al}^{3+}$ was determined by high performance liquid chromatography and atomic absorption spectroscopy, respectively. Sorption experiments were carried out using dialysis. Copolymer aqueous solution in ultrapure water at a concentration equal to 5 g. $\mathrm{L}^{-1}$ were introduced in a tubular ester cellulose dialysis membrane (molecular weight cut-off of $2000 \mathrm{Da}$ ). The latter was then immersed in a $100 \mathrm{~mL}$ bulk solution containing $5 \mathrm{~g} . \mathrm{L}^{-1}$ of $\mathrm{Ni}^{2+}$ or $\mathrm{Al}^{3+}$ ions, in order to be in large excess of metallic cations with respect to the number of phosphonic acid complexing groups borne by the copolymers. The latter in the inner solution could not migrate in the bulk solution because the molecular weight of copolymer chains was higher than the molecular weight cut-off of the dialysis membrane. The amount of $\mathrm{Ni}^{2+}$ or $\mathrm{Al}^{3+}$ ions trapped by the copolymer was determined by measuring the concentration of $\mathrm{Ni}$ or $\mathrm{Al}$ cations in the bulk solution before and after sorption experiments, at $\mathrm{pH}$ equal to 7 at $25^{\circ} \mathrm{C}$.

First sorption experiments were carried out with poly(2-ethyl-2-oxazoline) and poly(2-ethyl2-oxazoline)-stat-poly(ethyleneimine) polymers. POx showed negligible complexation properties whereas POx-st-PEI proved to be a little bit more efficient (Table 3 ). This result was not surprising, as secondary amines already proved to complex with metallic cations. ${ }^{28}$ Sorption percentage was determined comparing the moles number of metallic cations complexed to the moles number of ethyleneimine units (the latter being equal to 0.112 and $0.116 \mathrm{mmol}$ (see Supporting Information) for POx-st-PEI prepared from synthesized or commercial POx, respectively. Additionally, it was assumed that one complexing group was able to sorb one cation. As the percentages of sorption were low for both POx-st-PEI, complexation by secondary amine functions were considered as negligible for further experiments with $h$ POx-st-PEI-APC1 or hPOx-st-PEI-DAAmEP, especially since functionalization by APC1 or DAAmEP directly impacted these groups.

Concerning phosphonic acid-based polyoxazolines, it is important to notice that, as for the study of sorption on POx-st-PEI, experiments were carried out with a large excess of metallic cations to favor the sorption of one metallic cation per phosphonic acid group. ${ }^{34}$ Concentrations of nickel and aluminum ultrapure water solutions were measured at $1.562 \mathrm{mmol}^{-\mathrm{L}^{-1}}$ (Table S1, Supporting Information), and $1.208 \mathrm{mmol}^{-1}$ (Table S2, Supporting Information)after dilution by 10 , which was necessary to make the analysis. Both 
$h$ POx-st-PEI-APC1 and hPOx-st-PEI-DAAmEP

$\mathrm{Al}^{3+}$ (Table 3). Obtained sorptions were in were efficient for the complexation of $\mathrm{Ni}^{2+}$ or

TABLE 3. Experimental results for the sorption of $\mathrm{Ni}^{2+}$ and $\mathrm{Al}^{3+}$ metallic cations onto the different obtained copolymers

\begin{tabular}{|c|c|c|c|c|c|c|}
\hline \multirow{2}{*}{ Polymer } & \multirow{2}{*}{$\begin{array}{c}\mathrm{M}_{\mathrm{n}}^{\mathrm{c}} \\
\left(\mathrm{g} \cdot \mathrm{mol}^{-1}\right)\end{array}$} & \multirow{2}{*}{$\begin{array}{l}\mathrm{C}_{\mathrm{Ph}}{ }^{\mathrm{d}} \\
(\mathrm{mM})\end{array}$} & \multicolumn{2}{|c|}{ Complexed $\mathrm{Ni}^{2+\mathrm{e}}$} & \multicolumn{2}{|c|}{ Complexed $\mathrm{Al}^{3+\mathrm{f}}$} \\
\hline & & & $(\mathrm{mM})$ & (\%) & $(\mathrm{mM})$ & (\%) \\
\hline POx (synthesized) & 10400 & - & negligible & negligible & negligible & negligible \\
\hline POx (prepared) & 20000 & - & negligible & negligible & negligible & negligible \\
\hline POx-st-PEI ${ }^{a}$ & 8900 & - & 0.006 & 5.3 & 0.005 & 4.5 \\
\hline POX-st-PEI ${ }^{b}$ & 17700 & - & 0.004 & 3.4 & 0.003 & 2.6 \\
\hline$h P O x-s t-P E I-A P C 1^{a}$ & 10200 & 0.040 & 0.030 & 75 & 0.030 & 75 \\
\hline$h$ POx-st-PEI-DAAmEP & 11200 & 0.058 & 0.048 & 83 & 0.044 & 76 \\
\hline$h P O x-s t-P E I-A P C 1^{b}$ & 21900 & 0.057 & 0.040 & 70 & 0.034 & 60 \\
\hline$h$ POx-st-PEI-DAAmEP & 21000 & 0.043 & 0.034 & 79 & 0.031 & 72 \\
\hline
\end{tabular}

a copolymer prepared from synthesized poly(2-ethyl-2-oxazoline); ${ }^{b}$ copolymer prepared from commercial poly(2-ethyl-2oxazoline); ${ }^{c}$ calculated from the number of each unit multiplied its corresponding molecular weight; ${ }^{d}$ number of moles of phosphonic acid groups per liter: $\mathrm{C}_{\mathrm{ph}}=$ (mass of polymer $/ \mathrm{M}_{\mathrm{n}}$ of polymer) $\mathrm{x}$ number of phosphorus functionalized units per liter; ${ }^{\mathrm{e}}$ concentrations were determined by HPLC; ${ }^{f}$ concentrations were determined by AAS

accordance with results already published in the literature concerning phosphonic acid groups. ${ }^{29}$ Concerning $\mathrm{Ni}^{2+}$ cations, best sorption properties were obtained for the copolymer with the lowest molecular weight functionalized by acrylamide molecule (83\%). Copolymer modified using acrylate derivative also led to good sorption. When higher molecular weight copolymer was used, sorption properties slightly decreased, which could be explained by a likely higher steric hindrance induced by complexation. $\mathrm{Al}^{3+}$ cations were also efficiently retained by the phosphonic acid-based polyoxazolines, with percentages of complexed cations higher than $60 \%$. As for nickel, sorption was slightly better with lower molecular weight derivative and with functionalization with DAAmEP acrylamide. Additionally, from experimental sorption results obtained on POx$s t$-PEI, we concluded that remaining PEI units in $h$ POx-st-PEI-APC1 or $h$ POx-st-PEI-DAAmEP had a negligible effect on complexation. These preliminary results have to be confirmed by achieving a more detailed study, varying experimental conditions such as $\mathrm{pH}$, ionic strength, etc. Competitive conditions ( $\mathrm{Ni}$ vs Al) must be also considered. To conclude, preliminary sorption experiments permitted to prove that the developed well-defined water soluble phosphonic acid-based poly(2-ethyl-2oxazoline)s were good candidates for the complexation of metallic cations. As a result, such materials could be used in polymerenhanced ultrafiltration processes where watersoluble polymers are necessary to rapidly complex cations before filtration. Polyoxazoline derivatives are of great interest as they proved to be biocompatible and non-toxic.

\section{CONCLUSIONS}

This work focused on the development of valuable water-soluble phosphonic acid-based poly(2-ethyl-2-oxazoline) that could be employed for the complexation of metallic cations. First, synthesis of poly(2-ethyl-2oxazoline)-stat-poly(ethyleneimine) (POx-st-PEI) with control over the percentage of PEI unit was achieved by hydrolysis of poly(2-ethyl-2oxazoline) in acidic medium. $20 \%$ hydrolysis was chosen to maintain water-solubility of the produced statistical copolymers. Then, the latter were successfully functionalized with either dimethyl(acryloyloxymethyl) phosphonate (APC1) or diethyl-2(acrylamido)ethyl phosphonate (DAAmEP) using Michael reaction. Finally, phosphonated esters 
were hydrolyzed to produce phosphonic acid groups, which are known in the literature to efficiently complex with metallic cations. As a result, preliminary sorption experiments were achieved towards nickel or aluminum cations. Obtained sorption proved that the statistical copolymers developed were efficient for the complexation of both divalent and trivalent cations and that molecular weight of the copolymers and the use of APC1 or DAAmEP only slightly influenced sorption capacities.

The originality of the described work was based on the development of original water-soluble organic materials that could be employed for water treatment, prepared from biocompatible, non-toxic poly(2-ethyl-2-oxazoline)s. Preliminary sorption results showed the potential of these well-defined phosphonic acid-based poly(2-ethyl-2-oxazoline). Indeed, these copolymers showed good sorption properties toward nickel or aluminum. Additional experiments have to be achieved to confirm complexation results. They will also be devoted to a detailed study of the complexation properties of the copolymers. In particular, sorption will be studied in competitive conditions mixing different metallic cations (cobalt, zinc, cadmium, lead, and copper, for instance). Other components, such as manganese (II) nitrate or calcium (II) carbonate, will be also added to obtain simili, more representative of a real water effluent. Biocompatibility and toxicity of the copolymers will be considered. Obtained results will be reported in a forthcoming publication.

\section{ACKNOWLEDGEMENTS}

The authors thank the "Region Occitanie / Pyrénées - Méditerranée " for co-funding this work (BTB fellowship) and Benedicte Prelot for her help concerning the determination of nickel and aluminum concentrations in sorption experiments.

\section{REFERENCES AND NOTES}

1. G. K. Sarma, S. Sen Gupta, K. G. Bhattacharyya. Environmental Science and Pollution Research 2019, 26, 6245-6278.

2. L. Y. Jun, N. M. Mubarak, M. J. Yee, L. S. Yon, C. H. Bing, M. Khalid, E. C. Abdullah. Journal of Industrial and Engineering Chemistry 2018, 67, 175-186.

3. A. Pratush, A. Kumar, Z. Hu. International Microbiology 2018, 21, 97-106.

4. Z. Rahman, V. P. Singh. Environmental Monitoring and Assessment 2019, 191, 21.

5. T. A. Kurniawan, G. Y. S. Chan, W. H. Lo, S. Babel. Chemical Engineering Journal 2006, 118, 83-98.

6. Guidelines for Drinking-water Quality - Fourth edition incorporating the first addendum; World Health Organization, 2017.

7. G. Elias, S. Diez, C. Fontas. Journal of Hazardous Materials 2019, 371, 316-322.

8. V. Thangaraj, A. Bhaskarapillai, S. Velmurugan. Journal of Hazardous Materials 2020, 354, 121481.

9. D. Humelnicu, M. M. Lazar, M. Ignat, I. A. Dinu, E. S. Dragan, M. V. Dinu. Journal of Hazardous Materials 2020, 381, 120980.

10. M. Arias-Paic, K. M. Cawley, S. Byg, F. L. Rosario-Ortiz. Water Research 2016, 88, 981989.

11. M. Galizia, F. M. Benedetti, D. R. Paul, B. D. Freeman. Journal of Membrane Science 2017, 535, 132-142.

12. J. Charles, C. Bradu, N. Morin-Crini, B. Sancey, P. Winterton, G. Torri, P.-M. Badot, G. Crini. Journal of Saudi Chemical Society 2016, 20, 185-194.

13. J. T. T. Foster, Y. Hu, T. H. Boyer. Separation and Purification Technology 2017, 175, 229-237.

14. A. Murray, B. Ormeci. Journal of environmental sciences 2018, 8-16.

15. P. K. Sahu, R. Jaiswani. International Journal of Advanced Research, Ideas and Innovations in Technology 2018, Volume 4, 465-481.

16. A. J. Hargreaves, P. Vale, J. Whelan, L. Alibardi, C. Constantino, G. Dotro, E. Cartmell, P. Campo. Clean Technologies Environmental Policy 2018, 20, 393-402. 
17. U. Habiba, T. A. Siddique, T. C. Joo, A. Salleh, B. C. Ang, A. M. Afifi. Carbohydrate Polymers 2017, 157, 1568-1576.

18. N. Chitpong, S. M. Husson. Journal of Membrane Science 2017, 523, 418-429.

19. K. Sunil, G. Karunakaran, S. Yadav, M. Padaki, V. Zadorozhnyn, R. K. Pai. Chemical Engineering Journal 2018, 348, 678-684.

20. Y. F. Huang, X. S. Feng. Journal of Membrane Science 2019, 586, 53-83.

21. J. Sanchez, C. Espinos, F. Pooch, H. Tenhu, G. D. C. Pizarro, D. P. Oyarzun. Reactive and Functional Polymers 2018, 127, 67-73.

22. B. Lam, S. Déon, N. Morin-Crini, G. Crini, P. Fievet. Journal of Cleaner Production 2018, 171, 927-933.

23. O. D. Kochkodan, V. M. Kochkodan, V. K. Sharma. Journal of Environmental Science and Health, Part A 2018, 53, 33-38.

24. I. Korus, K. Piotrowski. Desalination and water Treatment 2017, 64, 447-455.

25. M. K. Aroua, F. M. Zuki, N. M. Sulaiman. Journal of Hazardous Materials 2007, 147, 752758.

26. R. Molinari, T. Poerio, P. Argurio. Chemosphere 2008, 70, 341-348.

27. K. Trivunac, S. Stevanovic. Chemosphere 2006, 64, 486-491.

28. V. Beaugeard, J. Muller, A. Graillot, X. Ding, J. J. Robin, S. Monge. Reactive and Functional Polymers 2020, 152, 104599.

29. A. Graillot, D. Bouyer, S. Monge, J. J. Robin, C. Faur. Journal of Hazardous Materials 2013, 244-245, 507-515.

30. K. Ohta. Bulletin of the Chemical Society of Japan 1992, 65, 2543-2545.

31. H. Tokuyama, T. Yoshida, L. L. He. Industrial \& Engineering Chemistry Reseach 2011, 50, 10270-10277.

32. V. I. Grachek, A. A. Shunkevich, R. V. Martsynkevich. Russian Journal of Applied Chemistry 2011, 84, 1335-1340.

33. D. Gomes Rodrigues, S. Monge, S. PelletRostaing, N. Dacheux, D. Bouyer, C. Faur. Chemical Engineering Journal 2019, 371, 857867.
34. A. Graillot, D. Bouyer, S. Monge, J. J. Robin, P. Loison, C. Faur. Journal of Hazardous Materials 2013, 260C, 425-433.

35. A. Graillot, C. Cojocariu, D. Bouyer, S. Monge, S. Mauchauffe, J. J. Robin, C. Faur. Separation and Purification Technology 2015, 141, 17-24.

36. A. Graillot, S. Djenadi, C. Faur, D. Bouyer, S. Monge, J. J. Robin. Water science and technology 2013, 67, 1181-1187.

37. O. Abderrahim, M. A. Didi, B. Moreau, D. Villemin. Solvent Extraction and Ion Exchange 2006, 24, 943-955.

38. O. Abderrahim, M. A. Didi, B. Moreau, D. Villemin. Scientific Study and ResearchChemistry and Chemical Engineering Biotechnology Food Industry 2007, 8, 129-141.

39. O. Abderrahim, M. A. Didi, D. Villemin. Journal of Radioanalytical and Nuclear Chemistry 2009, 279, 237-244.

40. N. Ferrah, O. Abderrahim, M. A. Didi, D. Villemin. Desalination 2011, 269, 17-24.

41. V. M. Ramos, N. M. Rodríguez, M. F. Díaz, M. S. Rodríguez, A. Heras, E. Agulló. Carbohydrate Polymers 2003, 52, 39-46.

42. T. Oshima, K. Kondo, K. Ohto, K. Inoue, Y. Baba. React. Funct. Polym. 2008, 68, 376-383.

43. M. Igura, M. Okazaki. Journal of Hazardous Materials 2010, 178, 686-692.

44. M. Igura, M. Okazaki. Journal of Applied Polymer Science 2012, 124, 549-559.

45. A. A. M. A. Nada, M. L. Hassan. Journal of Applied Polymer Science 2003, 89, 2950-2956.

46. A. M. A. Nada, M. A. Eid, A. I. Sabry, M. N. Khalifa. Journal of Applied Polymer Science 2003, 90, 97-104.

47. D. Le, F. Wagner, M. Takamiya, I. L. Hsiao, G. G. Alvaradejo, U. Straehle, C. Weiss, G. Delaittre. Chemical Communications 2019, 55, 3741-3744.

48. A. Oudin, J. Chauvin, L. Gibot, M. P. Rols, S. Balor, D. Goudouneche, B. Payre, B. Lonetti, P. Vicendo, A. F. Mingotaud, V. Lapinte. Journal of Materials Chemistry B 2019, 7, 4973-4982.

49. B. Verbraeken, B. D. Monnery, K. Lava, R. Hoogenboom. Eur. Polym. J. 2017, 88, 451-469. 
50. N. Oleszko-Torbus, A. Utrata-Wesolek, M. Bochenek, D. Lipowska-Kur, A. Dworak, W. Walach. Polymer Chemistry 2020, 11, 15-33.

51. M. A. Mees, R. Hoogenboom. Polymer Chemistry 2018, 9, 4968-4978.

52. A. Graillot, S. Monge, C. Faur, D. Bouyer, J. J. Robin. Polymer Chemistry 2013, 4, 795-803.

53. V. R. de la Rosa, E. Bauwens, B. D. Monnery, B. G. De Geest, R. Hoogenboom. Polymer Chemistry 2014, 5, 4957-4964.

54. H. M. L. Lambermont-Thijs, F. S. van der

Woerdt, A. Baumgaertel, L. Bonami, F. E. Du
Prez, U. S. Schubert, R. Hoogenboom. Macromolecules 2010, 43, 927-933.

55. G. Gonzalez, X. Fernandez-Francos, A. Serra, M. Sangermano, X. Ramis. Polymer Chemistry 2015, 6, 6987-6997.

56. C. Hoffmann, M. C. Stuparu, A. Daugaard, A. Khan. Journal of Polymer Science PArt A: Polymer Chemustry 2015, 53, 745-749.

57. B. Canniccioni, S. Monge, G. David, J. J. Robin. Polymer Chemistry 2013, 4, 3676-3685. 
Belkacem Tarek Benkhaled, Titouan Montheil, Vincent Lapinte, Sophie Monge

Hydrosoluble phosphonic acid functionalized poly(2-ethyl-2-oxazoline) chelating polymers for the sorption of metallic cations

TEXT

Synthesis of well-defined phosphonic acid-based poly(2-ethyl-2-oxazoline) is described. For such purpose, poly(2-ethyl-2-oxazoline) are functionalized with phosphonated acrylate or acrylamide, and hydrolysis of phosphonated ester groups is achieved, leading to phosphonic acid groups that can be used for the sorption of metallic cations. The developed materials, based on non-toxic and biocompatible polyoxazolines, represent a new opportunity for materials that can be employed in polymer enhanced ultrafiltration processes for water treatment.

GRAPHICAL ABSTRACT FIGURE

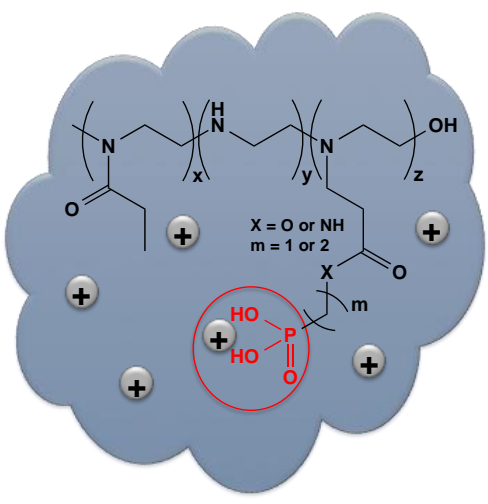

